being unexpected and unexplained and subsequently being diagnosed as COVID-19 post-mortem, concerns around care in those dying with a known diagnosis of COVID-19, or coincidental SARS-CoV-2 infection with a cause of death unrelated to viral infection. This had a significant impact on workloads at VIFM, ranging from changes in admission procedures, extensive viral testing, and contributions to contact tracing. Aspects of the management of these cases will be discussed, along with the pathological aspects of some of these presentations.

\section{VACCINATION DEATHS AND THE SAMOAN MEASLES OUTBREAK}

$\underline{\text { Linda Iles }}$

Victorian Institute of Forensic Medicine, Melbourne, Vic, Australia

On July 6th 2018, two 1 year old infants died shortly after receiving the Measles Mumps Rubella (MMR) vaccine. Events over the following months amplified this tragedy. The investigation of these deaths will discussed, along with the events that culminated in an epidemic that resulted in the death of 83 people, predominantly children, in the Pacific nation.

\section{IS PORNOGRAPHY IMPACTING SEXUAL ASSAULT PRESENTATIONS?}

Kim Farrington

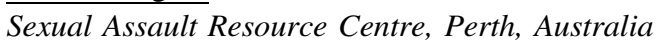

Pornhub is ranked the 9th most visited website in the world; $70 \%$ of visits to the site are on mobile devices; the average age an Australian boy first sees pornography is estimated to be 12 years old. Given that pornography is seemingly ubiquitous, is it influencing sexual assault presentations and how? This topic is explored using a clinical audit and case presentations.

\section{CLINICAL FORENSIC MEDICINE AND COVID-19 CHALLENGES: THE MELBOURNE EXPERIENCE}

Janine Rowse, Nicola Cunningham, Jo Ann Parkin Clinical Forensic Medicine, Victorian Institute of Forensic Medicine, Melbourne, Vic, Australia

The rapidly evolving context of the COVID-19 pandemic necessitated profound modifications to the provision of healthcare services globally. The concomitant requirements of lockdowns and social distancing and their subsequent isolating effects had marked ramifications for vulnerable individuals at risk of violence. The experiences of conducting sexual assault forensic examinations of suspected and confirmed COVID-19 positive patients in Melbourne hospital COVID-19 hot zones are presented, including the development of a modified forensic examination protocol. Additional clinical forensic issues specific to the pandemic context are discussed, including forensic 'mimics' of COVID-19 symptoms, clinical forensic service adaptations during Melbourne's second wave of community transmissions, and considerations of the impact of changes to service provision on the patient experience.

\section{EVIDENCE IN FORENSIC PRACTICE}

Maria Nittis

Clinical Forensic Medicine, Victorian Institute of Forensic Medicine, Australia

Evidence supporting much of clinical forensic medicine practice is deficient or dated. This presentation highlights the results from two local research projects which looked at various aspects of the sexual assault forensic examination.

1. Do they who slide first, slide best: Jurisdictions within Australia and internationally differ with regard to preference for who creates the smear from those swabs taken to find DNA from semen. This research sought to articulate the function of slide preparation in sexual assault and to identify whether slide preparation by the forensic examiner, at time of examination, was preferable to slide preparation by forensic laboratory staff, at a later date. It also provided a review of the limited research in this area and posed questions for potential future research.

2. Patient perception of forensic imaging: Historically, photography used in forensic documentation of injuries (especially genital injuries), sustained during an alleged sexual assault, has been controversial. This study explored the immediate and short-term experiential impacts of forensic photography from the victims' perspective and supports the case for the routine use of forensic photography, with patient consent.

\section{SWIPE RIGHT: THE EMERGENCE OF TECHNOLOGY FACILITATED SEXUAL ASSAULT IN CHILDREN AND ADULTS}

Janine Rowse $^{1,2}$, Siobhan Mullane ${ }^{2}$, Caroline Bolt ${ }^{1}$, $\overline{\text { Sanjeev Gaya }}^{1}$, Joanna Tully ${ }^{2}$

${ }^{1}$ Victorian Institute of Forensic Medicine, Melbourne, Vic, Australia; and ${ }^{2}$ Victorian Forensic Paediatric Medical Service, Melbourne, Vic, Australia

The use of technological platforms, such as social media and dating 'apps' to facilitate real-word social encounters between strangers is ubiquitous. Limited empirical data suggests there has been an increase in real-life contact sexual offences facilitated following people meeting online. We present the findings of a retrospective audit of a single clinician's forensic examination caseload from an Australian metropolitan adult clinical forensic medicine service. Concerningly, despite extensive research into online grooming of children, there is also a dearth of empirical research characterising technology facilitated contact sexual assault in children, with little additional known about the circumstances of these alleged incidents. A 14-year audit from an Australian paediatric clinical forensic medicine service is also presented, with common emerging features to technology facilitated sexual assaults discussed. The authors propose further large-scale research in this rapidly evolving area, to lead to informed preventive efforts and targeted education interventions.

\section{THINKING FAST AND SLOW IN THE EVALUATION OF INJURY PLAUSIBILITY IN CHILD PROTECTION}

Catherine Skellern

Child Protection and Forensic Medicine Service, Qld Childrens Hospital, Qld, Australia 
In evaluating injury in children, child protection paediatricians are tasked with determining whether the history given by parents or caregivers is valid with respect to explaining injury causation. This presentation summarises metacognition and in particular the dual processing theory of "fast and slow thinking" to explain how complex information in contexts of uncertainty is processed to produce decisions and responses, applied to a child protection context. An example is used that resembles abusive head trauma which focuses on understanding the difference between likelihood and plausibility in forensic interpretations of injury causation.

\section{ELDERLY SEXUAL ASSAULT}

\author{
$\underline{\text { Gregory Dayman }}$ \\ Yarrow Place, Womens and Childrens Hospital, Adelaide, SA, \\ Australia
}

Presentations of sexual assault in women and men aged 60 years and over are infrequent occurrences for both sexual assault medicine services and the forensic pathologist. Complainants range from fit, competent adults to the severely disabled, nonverbal and frail elderly. The forensic examination of these complainants can be challenging due to lack of competency to consent or provide history of the assault. The frail elderly victim may be unable to cooperate with the physical and anogenital examinations. Fragility of the ageing integument and the lack of oestrogenisation of the menopausal female genital tract increase the risk of injury from sexual trauma. The presence of co-morbid medical conditions can be confused with trauma. Rapid death following sexual assault in the geriatric victim is the result of mechanisms seen in sexual assault generally including strangulation and head trauma however can also be the result of severe anogenital injury. An understanding of co-morbid medical conditions occurring in geriatric anogenital tissues and the use of histology at autopsy can avoid misdiagnosis.

\section{TOXICOLOGY FROM A FORENSIC PHYSICIAN'S PERSPECTIVE AND HOW RECENT CHANGES IN THE STANDARDS MAY AFFECT YOU}

\author{
John A. M. Gall ${ }^{1,2,3}$ \\ ${ }^{1}$ Department of Paediatrics, The University of Melbourne, Vic, \\ Australia; ${ }^{2}$ Victorian Forensic Paediatric Medical Service, \\ Royal Children's Hospital and Monash Medical Centre, \\ Melbourne, Vic, Australia; and ${ }^{3}$ Era Health, Melbourne, Vic, \\ Australia
}

There are three Australian Standards that may have an impact upon forensic physicians in relation to their involvement with drug and alcohol testing. These are AS/NZS 4308:2003 Procedures for specimen collection and the detection and quantification of drugs of abuse in urine, AS/NZS 4760:2019 Procedure for specimen collection and the detection and quantification of drugs in oral fluid, and AS/NZS 3547:2019 Breath alcohol testing devices. The first two deal with the testing of specimens (urine and oral fluids) for medico-legal, workplace and court- directed purposes and cover the collection, on-site screening, and handling and dispatch of specimens to a laboratory for screening and/or confirmatory testing. The latter specifies requirements for the performance, testing and marking of breath alcohol testing devices for uses including personal, workplace and medical screening purposes. AS/NZS 4308:2003 is currently in the process of revision and the new Standard may be expected in 2022. The content of these three Standards will be discussed in relation to their implication for forensic physicians.

\section{NON-FATAL STRANGULATION AND THE GOLD COAST FORENSIC MEDICINE CLINICAL AND LEGAL EXPERIENCE}

$\underline{\text { Danika Fietz }}$

Forensic Medicine, Emergency Department, Gold Coast Hospital \& Health Service, Qld, Australia

Non-fatal strangulation (NFS) is considered an insidious form of domestic violence. In at least $50 \%$ of cases, strangulation leaves no obvious signs of injury and a proportion of NFS cases are minimised or go unreported. ${ }^{1-3}$ While they are rare overall, neck artery dissections are one of the most lethal and overlooked outcomes of strangulation and the most common cause of stroke in young people. ${ }^{4}$

A retrospective review study based on patients reporting NFS attending the Gold Coast Hospitals who were then referred for clinical forensic examinations during October 2018 to October $2020(n=66)$ revealed that $73 \%$ were offered medical imaging and of those who underwent medical imaging, $11 \%$ were confirmed to have internal injuries. Of these, $7 \%$ had neck artery dissections. This represents one neck artery dissection for every $15 \mathrm{CT} / \mathrm{MR}$ angiograms.

It remains unclear in the literature which patients should be medically imaged post NFS. The current review, albeit small, revealed that symptoms and signs such as neck tenderness or pain and/or neck bruising were present in all of those who were confirmed to have internal injuries.

This presentation will include comment on the role of medical evidence in NFS cases to date where possible.

\section{References}

1. Pritchard A, Reckdenwald A, Nordham C. Nonfatal strangulation as part of domestic violence: a review of research. Trauma Violence Abuse 2015; 18: 407-24.

2. Strack G, McClane G, Hawley D. A review of 300 attempted strangulation cases. Part I: criminal legal issues. J Emerg Med 2001; 21: 303-9.

3. Douglas H, Fitzgerald R. Strangulation, domestic violence and the legal response. Sydney Law Rev 2014; 36: 231-54.

4. UpToDate. Spontaneous and cervical artery dissection: clinical features and diagnosis. Mar 2019; cited 25 Oct 2020. https://www.uptodate.com/contents/spontaneous-cerebraland-cervical-artery-dissection-clinical-features-anddiagnosis?search=traumatic/cervical/artery/dissection \& source=search_result\&selectedTitle $=1 \sim 150 \&$ usage type=default\&display_rank=1\#H95541785 